\title{
MILTON SANTOS: \\ A PIONEER IN CRITICAL GEOGRAPHY FROM THE GLOBAL SOUTH ${ }^{\mathrm{i}}$
}

Thiago MACHADO ${ }^{1}$

O livro editado por Lucas Melgaço e Carolyn Prouse sobre Milton Santos pretende reintroduzir a obra e o pensamento do geógrafo brasileiro na audiência internacional da Geografia anglófona. Este é um projeto a que Melgaço se tem dedicado nos últimos anos e que está associado a outros resultados, tal como a realização de um simpósio na Antipode (2017) sobre Milton Santos, em que vários artigos foram publicados em inglês, e a tradução e edição, em parceria com Tim Clarke, de uma das últimas e mais sintéticas obras de Santos, Por uma outra globalização. (2017). É importante frisar que se trata de uma reintrodução ou reapresentação, pois na década de 1970 Milton Santos muito contribuiu com uma rede internacional de geógrafos, sobretudo, com aqueles que participavam da renovação crítica da disciplina, colaborando efetivamente nos primeiros anos da Antipode (Santos \& Peet, 1977), periódico norte-americano de Geografia Radical, e com a Herótode, na França. Além disso, o seu período de exílio o levou a lecionar em importantes universidades, não só do mundo francófono (Bourdeaux, Toulouse e Sorbonne), mas também anglófono, como Universidade de Toronto, Universidade de Columbia e Massachussets Institute of Technology.

Em 1979 foi publicado Shared Space: the two circuits of urban economy in underdeveloped countries, a tradução de O Espaço Dividido, originalmente publicado em francês, em 1975. Voltado ao estudo da realidade urbana dos países subdesenvolvidos, este trabalho foi o que mais repercussão obteve na Geografia de língua inglesa, sendo reconhecido por Terry McGee (1982) como "um marco histórico na interpretação da urbanização do terceiro mundo". Somado aos seus trabalhos publicados em inglês na Antipode (Santos, 1974a; 1977a; 1977b; 1977c; 1980) e ao resultado da sua atividade como visiting scholar em Toronto (Santos, 1975a), o Shared Space representa um período da sua trajetória cuja preocupação fundamental se referia aos dilemas do desenvolvimento e do subdesenvolvimento por meio do processo de urbanização. Por seu turno, as discussões apresentadas no livro editado por Melgaço e Prouse voltam-se a refletir as preocupações de uma fase mais madura do pensamento miltoniano, na qual a globalização impõe-se como tema central, deslocando a escala de estudo da formação social nacional para os vínculos entre os processos globais e os lugares.

Essa preocupação em explorar a última fase do pensamento de Milton Santos fica explícita na seleção, por parte dos editores, do texto O retorno do território para ser traduzido, compondo o segundo

1 Bolsista CAPES/FCT no Projeto "Saberes Geográficos e Geografia Institucional: influências e relações recíprocas entre Brasil e Portugal no século XX”, Doutorando em Geografia pela Universidade Federal Fluminense (Niteroi), Rua Miguel de Frias, 9, Icaraí, Niterói, RJ - CEP: 24220-900, Rio de Janeiro, Brasil. E-mail: machado.ta@gmail.com 
capítulo do livro. Publicado originalmente em 1994, este é um dos seus textos mais interessantes, mas também dos mais controversos, em que Milton Santos formula o conceito de território usado, contrastando-o com o que ele chama de território em si. Apesar de Moraes (2013) ter escrito todo um livro voltando-se a discutir o conceito de território em Milton Santos, a análise crítica do conceito de território usado é uma tarefa ainda a ser feita. Se, por um lado, o conceito carrega força argumentativa ao escapar da reflexão restrita ao Estado, de modo que esteja aberto ao uso que outros agentes imprimem ao território, é controversa a redução do território em si às formas espaciais, ao passo que o território usado seria um híbrido de objetos e ações, tal qual sua definição de espaço geográfico (Melgaço \& Prouse, 2017, p. 26-27). Parece repetir com o território a redução à materialidade que Claude Raffestin (1993) fez em relação ao espaço, ignorando esforços como o do próprio Raffestin em pensar o conceito de território de modo relacional, sem, para tanto, precisar adicionar adjetivações.

Ainda que o livro não tenha um capítulo exclusivamente comentando a tradução de $O$ retorno do território, o que seria uma grande contribuição, Melgaço e Prouse reconhecem no capítulo introdutório como o território usado é um conceito provocativo e lamentam que Milton Santos não tenha tido muito mais tempo de desenvolvê-lo apropriadamente. Originalmente formulado em 1994, o conceito de território usado não foi introduzido em A Natureza do Espaço (1996), principal obra de Milton Santos, mas é retomado em 2000 em O papel ativo da Geografia: um manifesto, assinado por Santos e seus colaboradores, e ainda em 2001 quando publica em co-autoria com Maria Laura Silveira O Brasil: sociedade e território no início do século $X X$. Neste último trabalho o território usado ganha centralidade na construção de sua interpretação do Brasil, pois, segundo os autores, pensar geograficamente o país é "fazer falar seu território".

Este conceito é empregado no sexto capítulo, no qual Frederico e Almeida tratam da economia política do território e do agronegócio no Brasil, ganha centralidade na discussão sobre o federalismo no Brasil empreendida por Fabrício Gallo no oitavo capítulo, e é empregado por Roberto Carvalho Aruzzo no décimo capítulo, no qual lida com a dimensão territorial das lutas das populações indígenas no país. Interessante notar que os três capítulos recorrem ao território usado segundo a perspectiva de atores sociais diferentes, o Estado, as empresas e outros grupos sociais, assumindo a preocupação em ressaltar o caráter múltiplo e relacional presente na própria formulação do conceito.

Porém, o tema central que o livro pretende enunciar, e que está em plena consonância com a preocupação de ampliar a audiência anglófona do Milton Santos, é a de ser ele um intelectual do "Sul Global". Alinhando-se às preocupações pós-coloniais ou decoloniais, Melgaço e Prouse questionam o eurocentrismo e o colonialismo acadêmico, que por meio de barreiras linguísticas hierarquizam e selecionam o pensamento intelectual. O próprio Milton Santos (1982) havia defendido uma "Geografia descolonizada”, tomando partido pela formulação das próprias teorias e contra a importação automática daquelas oriundas dos principais centros acadêmicos dos países centrais. É com tal objetivo que a teoria dos circuitos espaciais da economia urbana nos países subdesenvolvidos é construída, dando conta da especificidade do fenômeno da urbanização em tais países. Além disso, produz uma abordagem crítica às teorias dos lugares centrais, da difusão de inovações e dos polos de crescimento (Santos, 1974b; 1975b; 1978), ressaltando como as políticas de desenvolvimento, apoiadas no planejamento, conduziam à perpetuação da condição de subdesenvolvimento. O capítulo quatro, de autoria do francês Aurélien Reys, volta-se exatamente para a reflexão miltoniana do terceiro mundo, dedicando-se, assim, a apresentar a teoria dos circuitos espaciais da economia urbana e o seu contexto. Tal capítulo acaba por ser aquele que mais retrata o Milton Santos da década de 1970, o profícuo período em que foi levado à carreira internacional em decorrência do exílio.

No esforço de sistematizar o conjunto de artigos que compõem o livro, para além do capítulo introdutório dos editores e da tradução de $O$ retorno do território, podemos agrupá-los em três principais grupos. O primeiro se refere aos capítulos mais voltados a discussões eminentemente teóricas. Sarita 
Albagli centra a reflexão do terceiro capítulo no conceito de meio técnico científico-informacional, direcionando-o para a compreensão contemporânea da relação entre espaço e rede, reconhecendo a centralidade do fenômeno técnico na teorização miltoniana. Aurélien Reys, trata no capítulo seguinte da discussão sobre o terceiro mundo que Santos empreendeu, sobretudo, na década de 1970, ao passo que Eliza Pinto de Almeida (capítulo 5) lança mão do par dialógico tecnosfera e psicosfera para por Milton Santos em diálogo com Michael Foucault. Tomando o atendimento médico como tema de diálogo entre ambos autores, Almeida dispõe da perspectiva híbrida do espaço miltoniano, na qual a materialidade e a imaterialidade se convertem num conjunto de pares conceituais: fixos e fluxos, objetos e ações, tecnosfera e psicosfera.

O segundo conjunto de artigos apresenta propostas mais empíricas sem, contudo, ignorar a discussão e a aplicação dos conceitos desenvolvidos por Santos. Além disso, o que há em comum a todos é que são situados a partir da escala nacional brasileira, refletindo um dos projetos da carreira de Milton Santos, a produção de uma interpretação geográfica do Brasil. O capítulo seis, de autoria de Frederico e Almeida, trata do agronegócio no Brasil a partir do enquadramento da economia política do território, identificando as dinâmicas das forças centrípetas e centrífugas que associam os centros de gestão política e financeira à atividade em discussão, o agronegócio. O capítulo seguinte, de Luís Ângelo Aracri, resgata as críticas miltonianas ao planejamento e descreve como se deu o ordenamento territorial no século XX, com especial atenção para o ponto de inflexão nos anos de 1980 e 1990, em que o planejamento volta-se à integração da economia brasileira ao mercado internacional. No oitavo capítulo, Fabrício Gallo analisa o federalismo no Brasil, operacionalizando os conceitos de território usado e de evento, conforme desenvolvidos por Milton Santos, ressaltando como a estrutura federativa reproduz a desigualdades socioespaciais.

O Brasil permanece como tema no nono capítulo, no qual Júlia Adão Bernardes analisa a expansão da fronteira agrícola por meio dos circuitos espaciais de produção do agronegócio, de forma que o meio técnico-científico informacional também seja incrementado no território brasileiro. Como efeito dessa expansão da agricultura "moderna", os conflitos territoriais que promovem pressão sobre os territórios indígenas é discutido no décimo capítulo por Roberto Carvalho Aruzzo, associando estes sujeitos de resistência indígena ao que Milton Santos costumava chamar de homens lentos, homens dos tempos lentos, alheios aos fluxos globais financeiros e materiais que bem caracterizam a globalização.

Por fim, os dois últimos capítulos do livro destacam a dimensão ambiental, que no pensamento de Milton Santos são explicitados no papel da divisão do trabalho em promover a diversificação da natureza (Santos, 1996) e na conferência 1992: A redescoberta da natureza (Santos, 1992). No décimo primeiro capítulo, Paes e Levy tratam de como as unidades de conservação tornam-se modos de regulação da natureza, efetivando vínculos hierarquizados de normatização do território. Já no último capítulo, Francisco Toro volta-se a refletir uma nova ética para o engajamento responsável com a natureza a partir de quatro dimensões da obra miltoniana: ontológica, epistemológica, técnica e ética.

Em conjunto, o livro permite uma aproximação da obra de Milton Santos, mas mais que isto, da aplicação e operacionalização de muitos dos seus conceitos. Isto fica nítido na predileção dos capítulos em lidar com a escala nacional, dando continuidade à preocupação de Santos em pensar o território brasileiro, o que ficou registrado no seu último livro publicado (Santos \& Silveira, 2001). Permitir que a audiência da Geografia anglófona tenha contato com tais reflexões é de grande valia para que o diálogo acadêmico amplie seus canais de interlocução, e que a Geografia produzida no Brasil transite melhor nos fóruns internacionais. $\mathrm{O}$ caminho de apreciação crítica do próprio campo disciplinar da Geografia é ainda eivado de vieses, e este é um livro provocativo neste sentido, ao pretender explorar a riqueza das Geografias pensadas desde o "Sul". 


\section{REFERÊNCIAS BIBLIOGRÁFICAS}

Antipode. (2017). Antipode Symposium Introducing Milton Santos and "The Active Role of Geography”. Retrieved from https://antipodefoundation.org/2017/03/15/introducing-milton-santos-and-the-active-role-of-geography/

Terry, M. (1982). Book Review: Santos, M. 1979: Shared Space: the two circuits of urban economy in underdeveloped countries. Translated by Chris Gerry. Progress in Human Geography, 6(1), 146-148.

Melgaço, L., \& Prouse, C. (2017). Milton Santos: a pioneer in Critical Geography from the Global South. Switzerland: Springer International.

Moraes, A. C. R. (2013). O conceito de território na obra de Milton Santos [The concept of territory in Milton Santos's work]. São Paulo: Anna Blume.

Raffestin, C. (1993). Por uma Geografia do Poder [Toward a Geography of Power]. São Paulo: Editora Ática.

Santos, M. (2017). Toward an Other Globalisation: to the single thought to universal conscience (Melgaço \& Clarke, translators). Switzerland: Springer International.

Santos, M. (1996). A Natureza do Espaço [The Nature of Space]. São Paulo: Hucitec.

Santos, M. (1992). 1992: A Redescoberta da Natureza [The Rediscovery of Nature]. Estudos Avançados, 6(14), 95-106.

Santos, M. (1982). Novos rumos para a Geografia Brasileira [New trends to Brazilian Geography]. In Santos, M. (Ed), Novos rumos da Geografia Brasileira [New trends to Brazilian Geography] (pp. 209-219). São Paulo: Hucitec.
Santos, M. (1980). The Devil's Totality: how geographic forms diffuse capital and change social structures. Antipode, 1(3), 41-46.

Santos, M. (1979). Shared Space: the two circuits of urban economy in underdeveloped countries. London and New York: Methuen.

Santos, M. (1978). La Totalité du Diable [The Devil's Totality]. Espaces Temps, 8, 60-75.

Santos, M. (1977a). Society and Space: social formation as theory and method. Antipode, 9(1), 3-13.

Santos, M. (1977b). Spatial Dialectics: the two circuits of urban economy in underdeveloped countries. Antipode, 9(3), 49-60.

Santos, M. (1977c). Planning Underdevelopment. Antipode, 9(3), 86-98.

Santos, M. (1975a). Underdevelopment and Poverty: a geographer's view. Toronto: University of Toronto.

Santos, M. (1975b). Space and domination - a Marxist approach. International Social Science Journal, 27(2), 346-363.

Santos, M. (1974a). Geography, Marxism and underdevelopment. Antipode, 6(3), 1-9.

Santos, M. (1974b). Sous-développement et pôles de croissance économique et sociale [Underdevelopment and economic and social growth poles]. Tiers-Monde, 15(58), 271-286.

Santos, M., \& Silveira, M. L. (2001). O Brasil: território e sociedade no início do século XXI [The Brazil: territory and society at the beginning of 21 Century]. São Paulo: Record.

Santos, M., \& Peet, R. (1977). Introduction. Antipode, 9(1), 1-3.

i Melgaço, L., \& Prouse, C. (2017). Milton Santos: a pioneer in Critical Geography from the Global South. Switzerland: Springer International. 